\title{
CRACK ASSESSMENT OF A VERY THICK AND BLOC-LIKE CONCRETE MEMBER
}

\author{
Peter Joachim HEINRICH ${ }^{1}$, Dirk SCHLICKE ${ }^{1 *}$
}

\begin{abstract}
This paper presents the results of recent research activities on the hardening-induced stresses and the risk of cracking in very thick concrete members. These activities focus on a very large member with bloc-like dimensions. In contrast to typical member types such as ground slabs or foundation walls, bloc-like members are dominated by temperature gradients in all three dimensions (height, width and length) at the same time. Besides, the comparably high stiffness of these members leads to very low external restraints in cases of common applications. In these cases the members considered show distinct eigenstresses (residual stresses or self-balanced stresses) but only low restraint forces and moments. The assessment of the hardening-induced cracking of such members therefore requires a detailed analysis of the temperature and stress fields.

This contribution presents comprehensive investigations on the hardening-induced risk of cracking of a typical bloc-like concrete member in the form of an underwater foundation. The results of the simulation were compared with selected practical observations during the construction of the underwater foundation of a recently built bridge.
\end{abstract}

\section{Address}

1 University of Technology, Institute of Structural Concrete, Graz, Austria

* Corresponding author: dirk.schlicke@tugraz.at

\section{Key words}

- Mass concrete,

- Restraint stresses,

- Unreinforced concrete,

- Viscoelasticity,

- Risk of cracking,

- Crack width.

\section{INTRODUCTION}

In general, any concrete member that is affected by temperature-induced stresses due to hydration can be seen as a thick concrete member or mass concrete, see e.g. (ACI 116R, 2000). Mass concrete is also often defined by a minimum member dimension greater than $0.80 \mathrm{~m}$, see e.g. (ÖNORM EN 1992-1-1, 2011) or (ZTV-W215, 2012). Despite their thickness, the majority of ordinary mass concrete members usually have significantly larger dimensions in other directions. For example, a thick slab has a significant thickness; however, this thickness is minor compared to its areal dimensions. A thick wall also has a significant thickness; however, this thickness is usually several times less than its height (e.g., one criterion for a wall according to (ÖNORM EN 1992-1-1, 2011) is $H>5 \cdot B$ ), whereas the length of the wall exceeds the width by at least one order of magnitude. Members which do not fit into these definitions can be seen as bloc-like members. Typical examples are massive foundations. Some other exceptions are dam structures, which are not discussed in this contribution since these members are also strongly affected by the progress of construction in multiple stages.

Hydration-induced temperature fields as well as the resulting temperature stresses in bloc-like members differ from those in typical member types of slabs or walls. In particular, bloc-like members have

- a specific hydration-induced temperature field with an almost adiabatic warming in the interior of the member and distinct temperature gradients of height, width and length at the same time, and

- a comparably high axial stiffness due to their large cross section. 
Although the distinct temperature history causes significant temperature deformations in the form of axial elongation and shortening of the whole member, these deformations are hardly restrained in cases of common ground conditions in which such bloc-like members are needed. The main reason is the very low degree of external restraint due to the high axial stiffness of the member compared to the ground. In contrast, temperature gradients with regard to height, width and length are internally restrained by the deformation compatibility within the member. This causes distinct eigenstresses, which are also called residual or self-balanced stresses since they do not correspond with an external force or moment. The eigenstresses in mass concrete members can often exceed the local tensile strength and lead to cracks in the surface zone. In very thick members, these surface cracks can even reach depths up to several meters.

Basically, the surface cracking of very thick members is also subject to a geometrically set cracking, as presented in (Schlicke and Tue, 2015) for general member types of slabs and walls. In fact, adopting this conceptual model of geometrically set cracks to the specific behaviour of very thick bloc-like members enables a deformation-based design of a minimum reinforcement for the control of crack widths for these members as well. Depending on the width of the crack that has opened, it is even possible to achieve the unreinforced execution of these very thick bloc-like members.

As discussed in (Heinrich and Schlicke, 2014), current standards do not provide detailed regulations for the specific design of very thick and bloc-like members. Individual investigations, however, can provide sufficient information for the economic and sustainable control of crack widths on the basis of the deformation compatibility.

This contribution discusses the hardening-induced risk of cracking and the geometrically set cracking patterns of very thick and bloclike members on basis of the investigation of an underwater foundation of a large bridge. In detail, it presents numerical studies using a $3 \mathrm{D}$ volumetric finite element calculation model with a specifically developed thermomechanical-viscoelastic material model and the deformation-based analysis of the results. Furthermore, the results were discussed with special regard to their application in practice.

\section{PRELIMINARY REMARKS}

In general, this contribution aims for an economic and sufficient minimum reinforcement design of a massive underwater bridge foundation. Such bridge piers are designed to safely transfer loads into the ground, whereby the underwater part of the pier is usually predominantly compressed. However, even if cracking due to a load transfer can be excluded in the underwater part, temperature-induced eigenstresses may cause critical tensile stresses. Two typical stress states can be identified:
- in the hydration-induced warming phase, tensile stresses occur in the surface zone when the interior of the member (core) is compressed; and

- with ongoing cooling, the sign in both areas changes and initially tensile stresses in the surface zone become compressive stresses, whereby stresses in the core become tensile stresses.

Most likely, the tensile-stresses in the surface zone exceed the present tensile strength; therefore, it is no longer possible to generally exclude hardening-induced cracks in this area.

Altogether, a reliable statement concerning the stability of such structures calls for an investigation of the effect of possible cracking due to residual stresses. Furthermore, a realistic consideration of the viscoelastic concrete properties is of major importance in order to assess the cracking risk adequately. Both aspects have been systematically studied in several research projects and feasibility studies at the Institute of Structural Concrete at Graz University of Technology. This particular contribution belongs to a research project dedicated to the unreinforced execution of mass concrete structures (FFG843489).

\section{EXAMPLE: UNDERWATER FOUNDATION}

\subsection{Overview}

(Fig. 1) shows an example of the underwater foundation considered in its overall setting. All of the underwater parts can be classified as mass concrete structures with the smallest degree of thickness much greater than $0.8 \mathrm{~m}$. This contribution focuses on the middle pier. The actual dimensions of this part are $L / H / B=64 / 16 / 16$ m, which indicates a bloc-like member because $H \ll 5 \cdot B$ and $L / H \sim 3.5$.

The underwater foundation considered is completely below the water level, while the lower half of its height is integrated into the subsoil. It is assumed that this pier is casted in between a pit provided by sheet walls. Besides, it is assumed that the whole concrete bloc of the underwater foundation is casted in one go with fresh in fresh connected layers.

\subsection{Relevant Material Properties of the Concrete Used and the Subsoil}

A typical mass concrete with a strength class of C 20/25 was used for the pier. According to (ÖNORM EN 1992-1-1, 2011), this refers to $f_{\text {ctm }}=2.20 \mathrm{~N} / \mathrm{mm}^{2}$ as the mean tensile strength and a mean 28-day Young's modulus of $E_{\mathrm{cm}}=30000 \mathrm{~N} / \mathrm{mm}^{2}$. The maximum heat potential due to hydration of this concrete was assumed to be $88750 \mathrm{~kJ} / \mathrm{m}^{3}$,

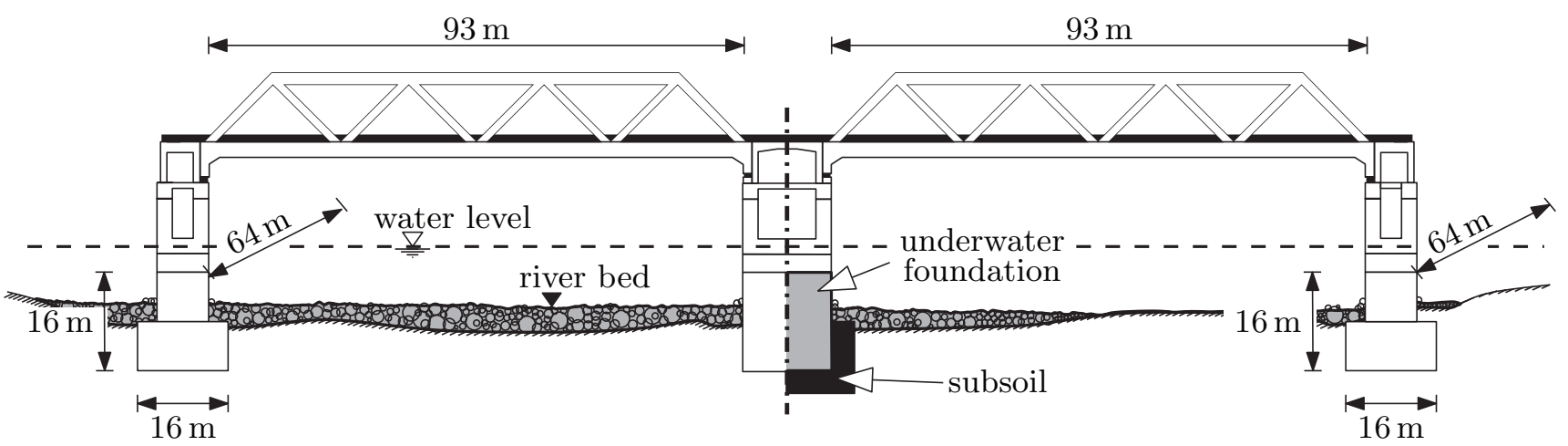

Fig. 1 Sketch of the situation and view of the finished bridge 
representing $2090 \mathrm{~kg}$ of CEM III/B 42.5 LH/HS. The thermal conductivity of this concrete varies between 3.0 and $2.1 \mathrm{~W} /{ }^{\circ} \mathrm{Cm}$, depending on the advancement of hydration. The concrete's specific heat capacity is considered to be constant at $2500 \mathrm{~kJ} /{ }^{\circ} \mathrm{Cm}^{3}$. The viscoelastic properties are considered with the creep behaviour according to (ÖNORM EN 1992-1-1, 2011) with consideration of the effect of drying with $h_{0}=2000 \mathrm{~mm}$ and $R H=60 \%$. In contrast to the normative regulation, it was distinguished between compressive and tensile creep according to the findings in (Schlicke, 2014). Besides, autogenous and drying shrinkage was neglected with regard to the comparably low autogenous shrinkage rate of the concrete used and the exclusion of external drying according to the present boundary conditions.

The subsoil was taken into account with a linear-elastic material behaviour with an elastic modulus of $100 \mathrm{MN} / \mathrm{m}^{2}$. Its thermal properties in the temperature simulation are a specific heat of $2100 \mathrm{~kJ} /{ }^{\circ} \mathrm{Cm}^{3}$ and thermal conductivity of $2.1 \mathrm{~W} /{ }^{\circ} \mathrm{Cm}$.

\section{CALCULATION MODEL}

The simulation of the hardening-induced stress history in mass concrete requires a comprehensive calculation model that uses well-established material models and appropriate boundary conditions. Here, a 3D volumetric finite element calculation model is generated using SOFiSTiK together with a specifically developed algorithm for the consideration of the complex viscoelastic behaviour in hardening concrete. Both are presented in the following subsections.

\subsection{Structural idealization in Finite Elements (FE)}

The structural FE model is shown in (Fig. 2). The model consists of volume elements for hardening concrete and volume elements for the surrounding soil. For both "regions", ordinary 8 node linear-elastic volume elements with linear shape functions were used. To reduce the complexity of the calculations and to decrease the computation time, the structural idealization represents only a quarter of the whole structure using symmetry conditions.
Within the model, the elements of concrete and soil are directly connected using the same nodes in their contact planes. In the temperature simulation this provides perfect heat flux between both materials and in the stress simulation a rigid connection between them. Slip or friction between both materials are excluded in order to provide the most unfavourable but still realistic restraining condition for the hardening concrete. In fact, the consideration of friction between the concrete member and the subsoil would firstly lead to a lower restraining condition due to the simultaneously occurring slip. On the contrary, the friction force can also be overestimated when the weakness of the subsoil is not taken into account, see e.g. (Schlicke and Tue, 2015).

The external interaction of the model with the environment is provided by additional boundary conditions. For the temperature simulation, heat flow conditions were included at the free surfaces. In detail, a conservative heat transfer coefficient of $20 \mathrm{~W} /{ }^{\circ} \mathrm{Cm}^{2}$ for stagnant water at the top and side surfaces was taken into account, whereas the planes of symmetry are modelled as adiabatic planes without any heat transfer. For the stress simulation, the whole model was bedded as follows: symmetry conditions in the symmetry planes and fixation of all nodes in the cutting planes of the soil body against displacement out of the plane.

In contrast to common modelling assumptions, the self weight of the concrete and possible uplift due to temperature gradients were not considered. Such assumption is justified in case of bloc-like members with significant self weight maintaining a permanent compression in the bedding plane.

\subsection{Thermo-mechanical material model}

In general, the simulation works with the thermo-mechanical material model for the coupled evolution of thermal and mechanical properties presented in (Schlicke, 2014) and (Schlicke and Tue, 2015). In particular, the model is implemented for each concrete element individually, basing upon the evolution of the so-called equivalent concrete age in each element. This equivalent concrete age is a state variable representing the maturity (effect of the actual concrete

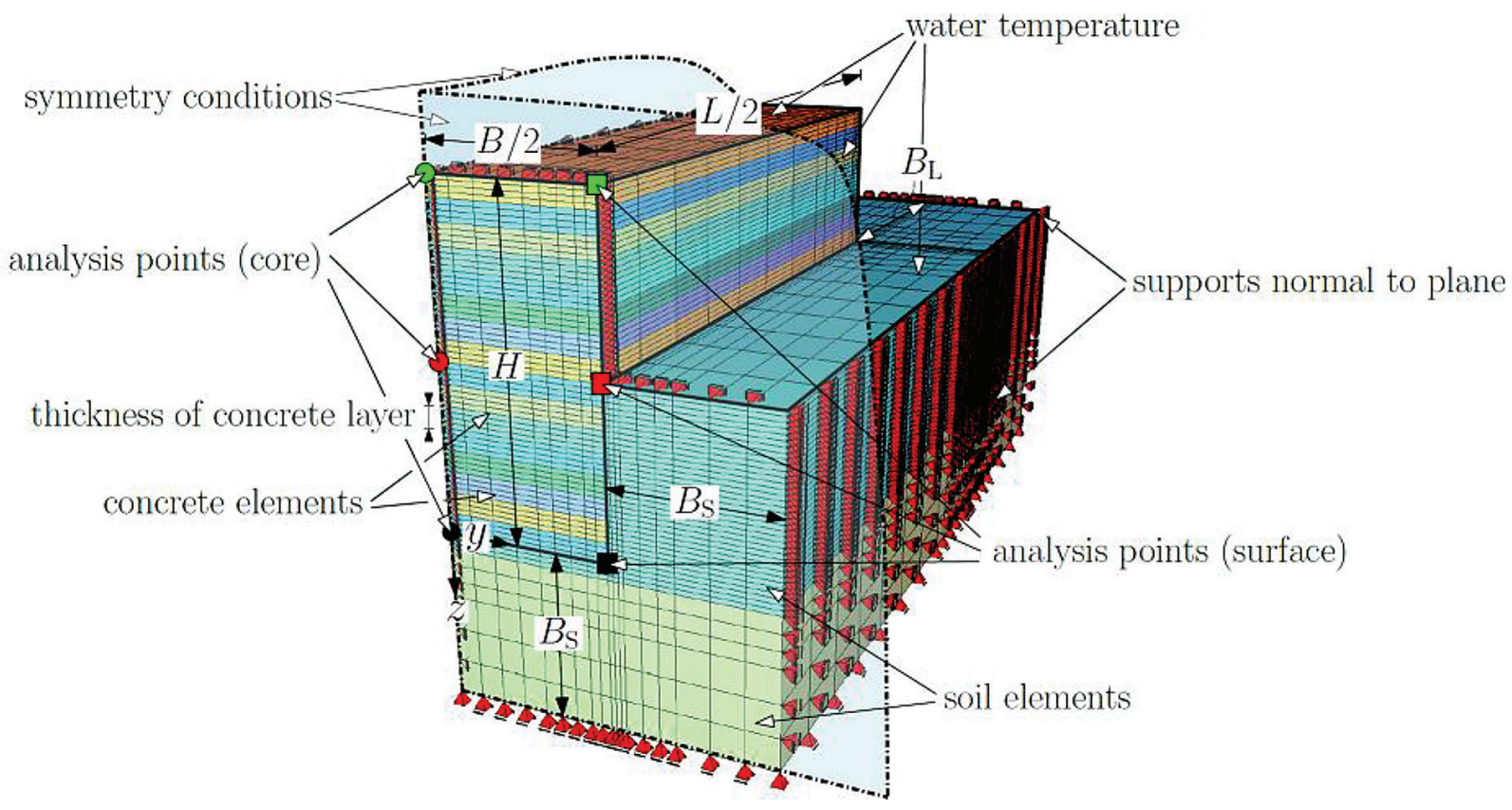

Fig. 2 Structural FE model of a massive foundation (pier) 
temperature on the rate of the hydration and hardening). Here, this temperature-dependent variable is determined in accordance with the approach of (Freiesleben et al., 1977). It furthermore controls the release of hydration, which is modelled with the approach given in (Jonasson, 1984). The (Wesche, 1993) model used for the description of the development of the strength also depends on the equivalent age.

In contrast to the model presented in (Schlicke, 2014) and (Schlicke and Tue, 2015), the viscoelastic effects are considered with the new deformation-based approach of (Heinrich, 2018) outlined in the following section.

\subsection{Consideration of the viscoelasticity}

An appropriate consideration of viscoelastic effects in hardening concrete is a challenging task and a lot of effort has been put into the development of numerical models to capture these effects. Usually, the viscoelastic behaviour is determined with creep tests and, based on these creep curves, the entire viscoelastic behaviour is described. A common method is to link specific age-dependent creep curves with time-dependent changes of stresses in the element. Hereby, additional viscoelastic deformation impacts are determined with regard to the prior stress history and imposed into the system as additional impacts using the Boltzmann principle of superposition. Although this is a common method, recent publications doubted the applicability of the principle of superposition for concrete in unloading phases. Therefore, (Schlicke, 2014) proposes a modified approach in which the viscoelastic potential of a time step is defined in relation to the global stress state and with further distinction between increase and decrease of stresses in this time step (loading or unloading). This promises a sound prediction of the resulting stresses and leads to very good agreements for the comparison of calculations of on-site stress measurements in various applications presented in (Schlicke, 2014) as well as the calculation of restraining frame experiments presented in (Jędrzejewska et. al., 2018). In general, the new approach was developed with regard to the proposed modifications of (Schlicke, 2014), however, it is formulated with a rheological model configured as a Kelvin (KV) chain in order to increase the performance significantly. Details can be found in (Heinrich, 2018) and (Fig. 3) shows a sketch of the model.

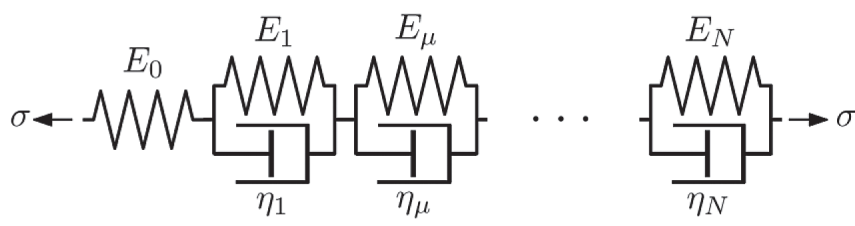

Fig. 3 Kelvin-chain model for the simulation of viscoelastic behavior

The KV-chain consists of a single spring and several KV units (a parallel arrangement of an elastic spring and a viscous dashpot) in series. All these elements have different parameters $E_{0}, E_{\mu}$ and $\eta_{\mu}$ $(\mu=1, \ldots, N) . E_{0}$ and $E_{\mu}$ are the stiffness of the springs and $\eta_{\mu}$ represent the viscosity of the dashpots. The model only delivers the creep strain, while the elastic deformation is provided by the FE framework. The model equation is derived for an ageing material. This means that with increasing time, each stress increment that acts on the model corresponds with a change in the model parameters $E_{\mu}$ and $\eta_{\mu}$.

Another achievement of (Heinrich, 2018) was an efficient method for the suitable fitting of the rheological model to the Eurocode creep model given in (EN 1992-1-1, 2011). This aims especially on the provision of a viable material model for design tasks without explicit information on the creep behaviour of the concrete. In detail, $E_{\mu}$ and $\eta$ can be determined analytically with an approximation of the retardation spectrum as proposed in (Bažant and Wu, 1988). With some additional modifications as shown in (Jirásek and Havlásek, 2014), it is possible to approximate the creep curves very well with low-order spectrae. Altogether, a good degree of accuracy (relative error $<1 \%$ ) is provided within a creep time lapse of about $10^{5}$ days by only 10 KV units.

\subsection{Calculation procedure}

The hardening of the concrete was simulated with discrete time and with respect to the construction process. In particular, the construction process was simulated with separate concrete layers (16 layers, thickness $=1 \mathrm{~m}$ each) that were always activated layer-by-layer, i.e., each one after $15 \mathrm{~h}$. This refers to a concreting speed of $68 \mathrm{~m}^{3} / \mathrm{h}$. The whole simulation lasts 17472 hours ( 2 years) in order to achieve the temperature equalization of the very thick member. For efficiency reasons the time step length was varied throughout the simulation, beginning with $\Delta t=1$ hour up to 168 hours and ending with $\Delta t=168$ hours after 8736 hours of simulation. In between, time step lengths of $\Delta t=2,6,12,24,48$ and 96 hours were included. Besides, it should be noted that a seasonal variation of the water-temperature was considered. It varies sinusoidally between $T_{\max }=18{ }^{\circ} \mathrm{C}$ (beginning of the casting) and $T_{\min }=3{ }^{\circ} \mathrm{C}$ within a year $(8736 \mathrm{~h})$.

\section{RESULTS OF THE STUDY}

\subsection{Method of analysis}

The development of the temperature and the stresses were assessed throughout the whole period of the simulation. A common distinction between early age stresses and cracking risk due to hardening, e.g. in the first 3 days after casting, and later stresses due to seasonal temperature variation in the service life is not possible in this case. The reason is the significant thickness of the member. This causes a very long period of the so called outflow of hydration heat which is already superimposed by the effect of seasonal temperature variations. Therefore, the crack assessment includes both the hardening-induced stressing and temperature stresses of the service life.

In particular, the temperature over time was analysed at 6 different points located in the cross section as marked in (Fig. 2), which shows 3 points over the member's height (top: green, middle: red and bottom: black) in the centre axis as well as at the side surface. The development of the resulting stresses was analysed at the same points by using the mean stress of the adjacent elements. The stresses have been assessed in $x$ - and $y$-direction, while the results in the $z$-direction are negligible. Besides, the temperature and stress fields were analysed at distinctive points in time.

\subsection{Development of the temperature}

The development of the temperature field is illustrated in (Fig. 4). It shows the temperature distribution in the evaluated $y z$-cross section after 1 week, 1 month, 5 months, 1 year, and 2 years. It can clearly be seen that the hydration heat causes a significant difference in temperature between the core of the member and the surface zone: The surface zone is directly affected by the ambient water and soil temperature. On the contrary, the temperature in the core increases according to almost adiabatic conditions. The reasons are the large dimensions of the pier, so that there is only a very slow temperature exchange between the core and the surface zone in the warming 


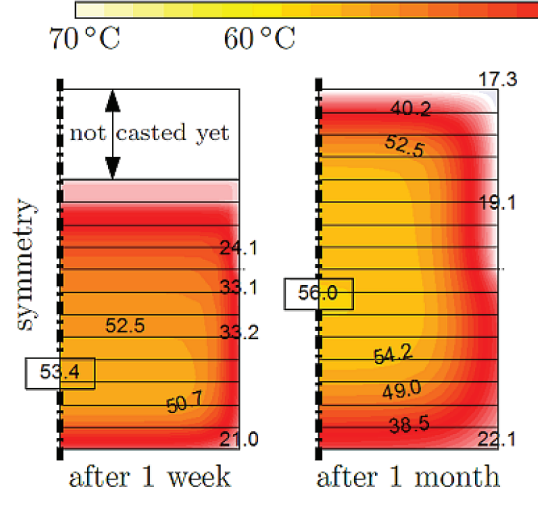

Fig. 4 Distribution of the temperature at certain moments

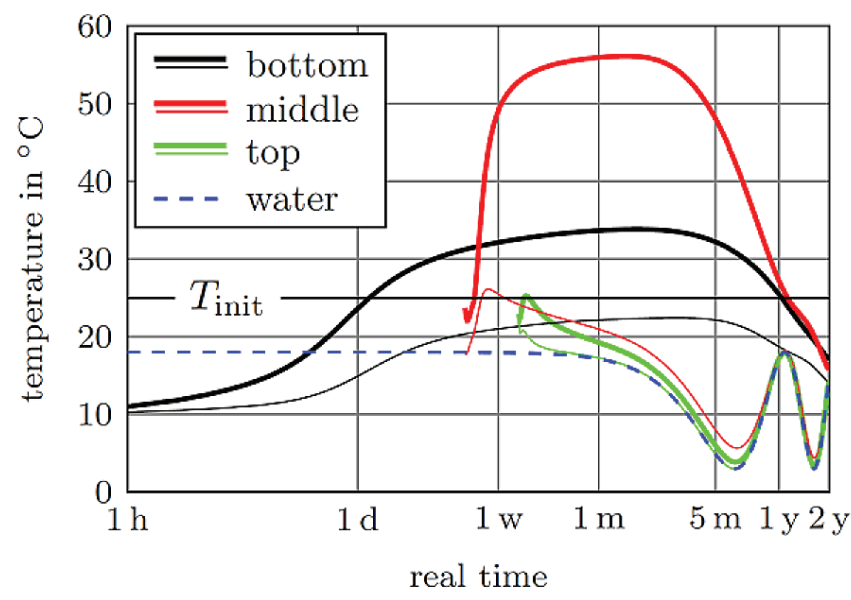

Fig. 5 Development of the temperature in measurement points

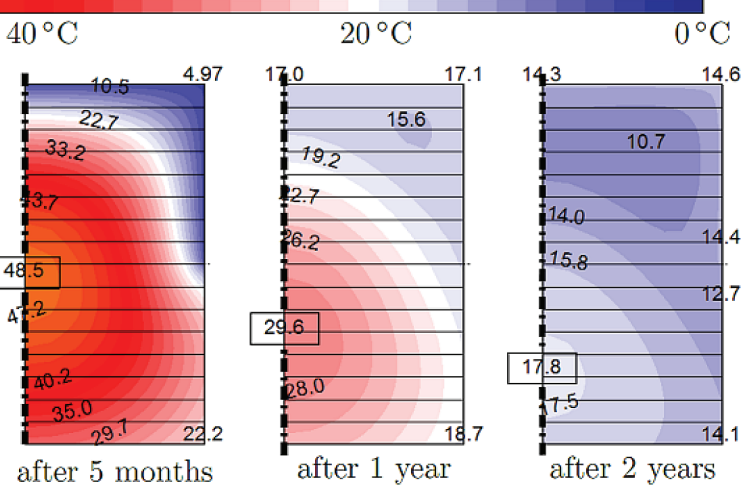

phase. Thus, distinct temperature gradients occur over the cross section's width and height.

Another important influence is the delay due to the construction process which causes a moving of the maximum temperature from the bottom to higher layers. The absolute temperature maximum is reached after 1 month between $H / 2$ and $H / 3$. Afterwards, the core starts to cool down, and the point of the maximum temperature moves at first up to $H / 2$ and later down again because of ongoing heat exchange with prior stored heat in the soil.

(Fig. 5) illustrates the development of the temperature at the specific measurement points (thick solid lines: points in symmetry plane; thin solid lines: surface). It can be seen that the maximum temperature of regions that are affected by the surrounding water do not significantly exceed the initial concrete temperature of $25{ }^{\circ} \mathrm{C}$ because the temperature in these points is directly emitted to the environment. A quite different kind of behaviour is noticeable in the surface points that are situated in the subsoil. The maximum temperature reaches in the symmetry plane about $33{ }^{\circ} \mathrm{C}$, which is approximately $10{ }^{\circ} \mathrm{C}$ higher than the initial concrete temperature $T_{\text {init }}$. Because of the soil's heat capacity, the temperature outflow is much slower compared to the points in the surface-zone surrounded by water.
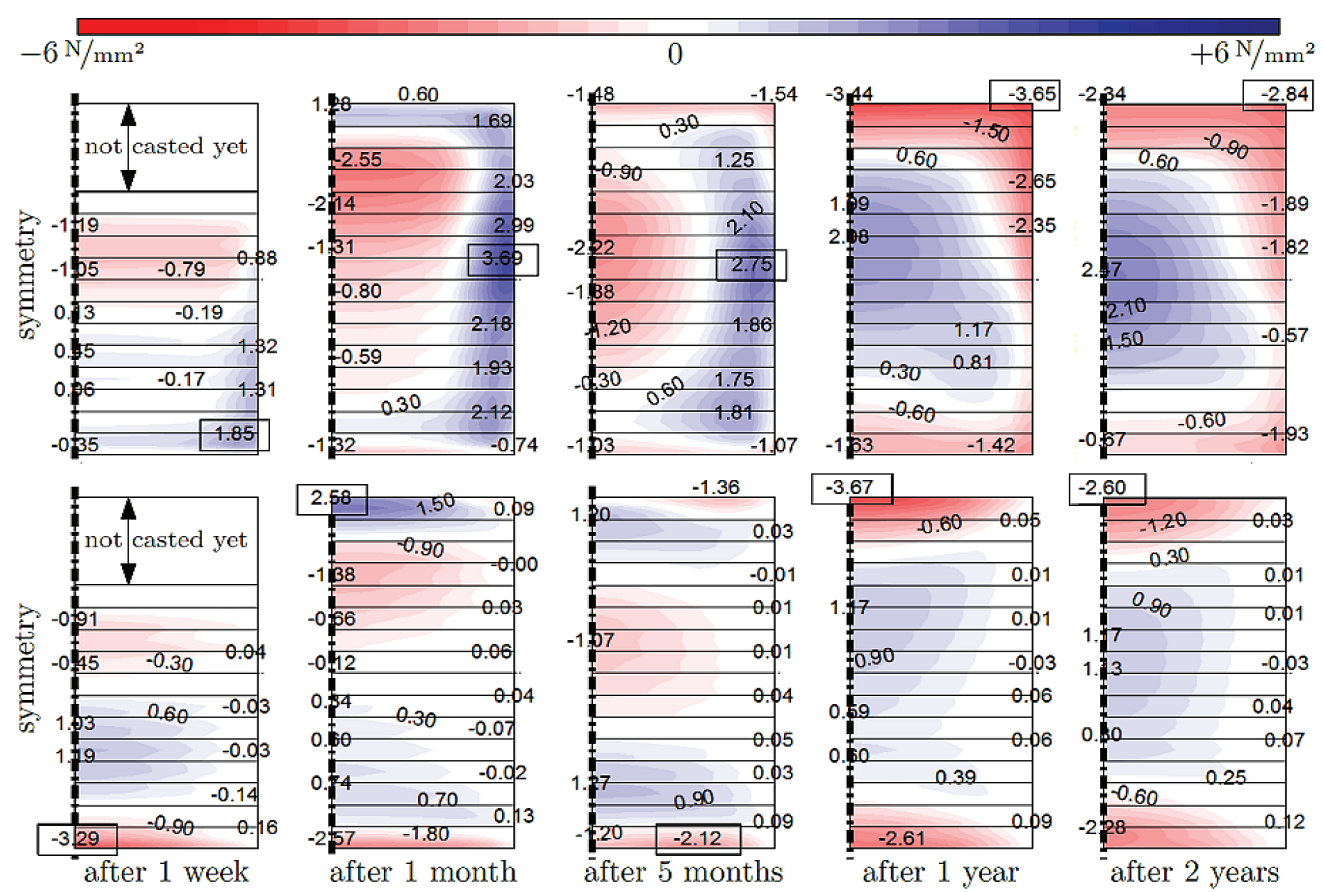

Fig. 6 Stress distribution (mean element stress) in $x$ (top row) and y-directions (bottom row) at certain moments 

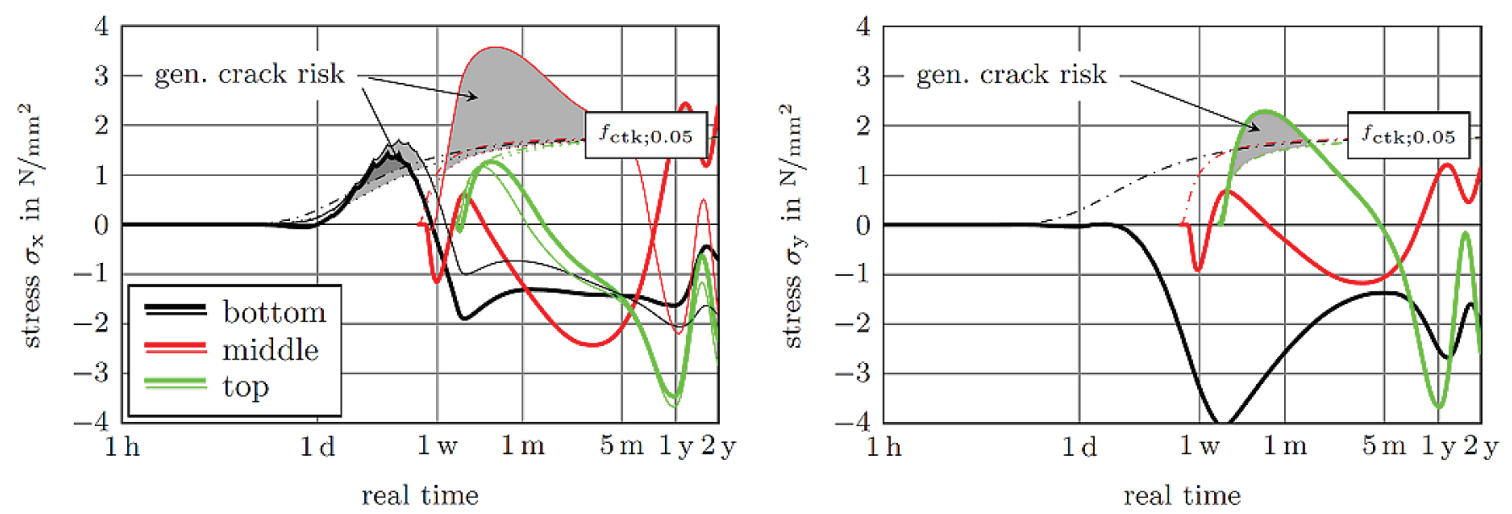

Fig. 7 Development of stress in measurement points in $x$ (left) and $y$ (right) directions

As expected, the absolute maximum temperature of $57{ }^{\circ} \mathrm{C}$ is reached in the core. The effect of the large dimensions is again noticeable in (Fig. 5). While the temperature in the surface zones follows the ambient temperature after about 1 month, the equalization of the temperature in the core occurs only after 1.5 years.

\subsection{Development of stresses}

The development of the stress fields is illustrated in (Fig. 4) for the stresses in $x$-direction (top row) and in $y$-direction (bottom row). It shows the stress distributions in the evaluated $y z$-cross section after 1 week, 1 month, 5 months, 1 year, and 2 years.

The stresses in $x$-direction are similarly distributed as the temperature field. In detail, the core and surface zone show stresses with different signs according to the temperature differences. The (colder) surface zone restrains the core zone's thermal expansion. Due to the inner equilibrium, this leads to compressive stresses in the core and tensile stresses in the surface zone at early ages. With ongoing cooling and hardening, the stress distribution changes its sign so that after about 1 year, the surface zone is fully compressed, while noticeable tensile stresses arise in the core zone.

The distribution of stresses in $y$-direction in the same cross section (Fig. 6, bottom-row), shows a somewhat different behaviour as the stresses in $x$-direction. In the first week comparably high compressive stresses occur at the bottom which are in equilibrium with the tensile stresses in the layers above. With ongoing time (after 1 month) significant tensile stresses occur at the top surface which are in equilibrium with the compressive stresses in the layers below. With ongoing cooling and hardening, the stress distribution becomes more and more symmetric with regard to the height, and the tensile stresses at the top finally result in compressive stresses. It should be noted that there are almost no $y$-stresses in the side surface since this area is hardly restrained in this direction.

The development of the $x$ - and $y$-stresses are drawn in (Fig. 7) for each 3 specific points in the core (thick solid lines) and surface zone (thin solid lines). The plots show also the evolution of the tensile strength. In particular, the $5 \%$ quantile of the present tensile strength $f_{\text {ctk:0.05 }}(t)$ is given as a lower boundary for the assessment of the cracking risk. It can clearly be seen that some $x$ - and $y$-stresses exceed this lower boundary extensively at around 3 weeks. Especially the $x$-stresses in the middle of the side surface (thin solid red lines, left graph) and the $y$-stresses in the symmetry plane at the top surface (thick green line, right graph). Besides, minor exceeding can be seen for $x$-stresses in the bottom zone ( $\sim 3$ days) and in the interior ( $\sim 1$ year).

It is common practice to assess the risk of cracking by comparing the present tensile strength with the calculated stresses in the mate- rial point or element. However, detailed information on the type of cracking to be expected is rather limited by such assessment. Therefore, a two-stage assessment was proposed by (Schlicke, 2014): In the first step the general risk of cracking is assessed by a comparison of the maximum stresses in the material point or element with $80 \%$ of $f_{\text {ctk:0.05 }}(t)$. If this is fulfilled, cracking can be safely excluded; and if not, cracking is to be expected in general. Such cracking includes at least microcracking or locally restricted surface cracks and leads at least to the reduction of eigenstresses (the non-linear part). The remaining stress parts (a uniformly and gradually distributed part) have to be assessed in the second step. These remaining stresses correspond with the restraint forces and moments and will cause macrocracks when the cracking forces and moments are exceeded. Thus, the stresses are now compared with the mean value of the actual tensile strength $f_{\mathrm{ctm}}(t)$.

\section{DISCUSSION}

\subsection{Assessment of the cracks}

Assessing the risk of macrocracks requires an analysis of the resulting stress distribution in each time step, see (Schlicke, 2014). For walls or slabs, this procedure can be simplified if approximation formulas are used. It is not possible to use these simplified formulas for bloc-like members like the pier investigated. The reason is that the stress distribution is not constant over the height and width at the same time. Therefore, a more sophisticated method has to be used; the details can be found in (Heinrich and Schlicke, 2016). The resulting stress parts have been determined for the $y z$ and $x z$-plane using this method. (Fig. 8) shows their course together with $f_{\mathrm{ctm}}(t)$.

It can be seen that the constant part is of minor importance compared to the linear parts. Although, the surrounding soil was considered conservatively with a rather high stiffness, the much higher stiffness of the pier leads to a very low degree of restraint. This causes a small resulting constant part for both directions considered. The noticeable linear parts are influenced by the thermal capacity of the subsoil, i.e., the bottom zone is warmer than the top zone, and the restraint of the curvature causes the resulting bending stresses, whereby the bending stresses in the $y$-direction are much smaller, because $B \ll L$.

Although, significant stresses result from the linearly distributed parts in the $x$-direction, they remain below $f_{\mathrm{ctm}}(t)$ and macrocracks can be excluded. This means that if cracks occur in the present case, they are mainly caused by the eigenstresses, which affect "only" the surface zone. The depth and width of these surface cracks as well as the distance between them can be determined with the conceptual model of geometrically set cracks due to restraint according to (Schlicke, 2014) and (Schlicke and Tue, 2015). Input values are the restrained 

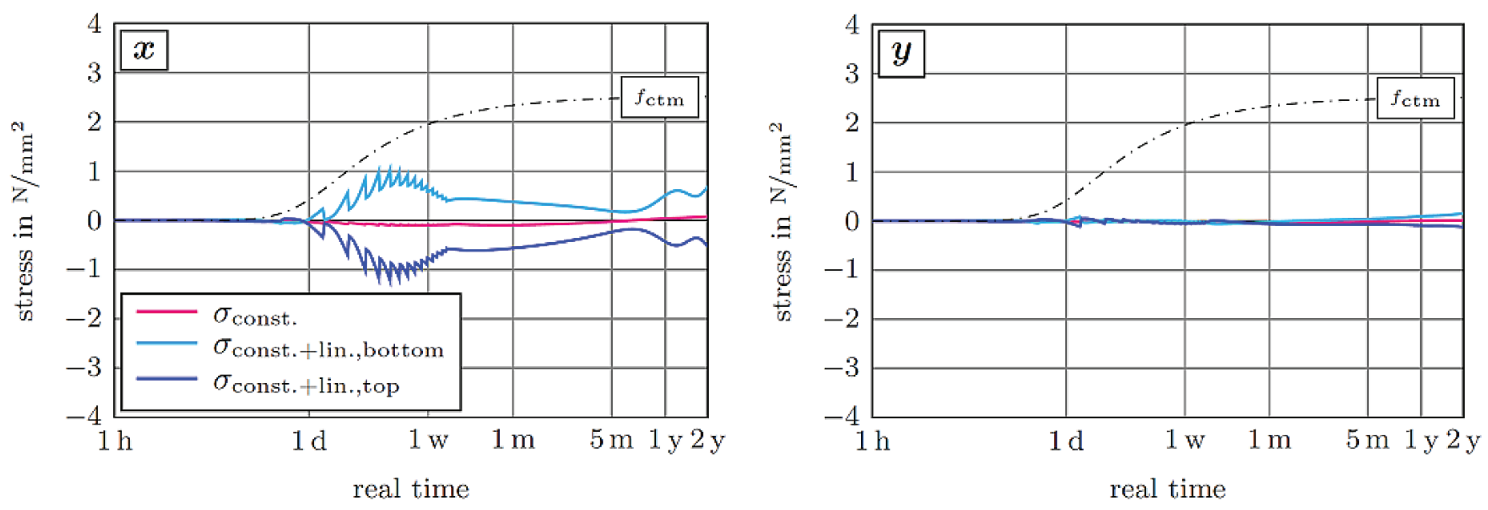

Fig. 8 Development of the constant and linear parts and their superposition

deformation according to the stresses and the elastic modulus as well as the depth of surface cracks to be expected. Both can be found in the FE calculation. For the decisive $x$-stresses, which cause transversal surface cracks beginning at the side surface and running over the top, it is: $\sigma=3.69 \mathrm{~N} / \mathrm{mm}^{2}, E_{\mathrm{cm}}(t)=30000 \mathrm{~N} / \mathrm{mm}^{2}$ and the depth can be assumed with $1 \mathrm{~m}$ by comparing the tensile stress distribution over the width with the present tensile strength. This indicates a geometrically set distance of the cracks of $1.2 \times 1 \mathrm{~m}=1.2 \mathrm{~m}$ and a crack width of $3.69 \mathrm{~N} / \mathrm{mm}^{2} / 30000 \mathrm{~N} / \mathrm{mm}^{2}$ x $1.2 \mathrm{~m} 10^{3}=0.15 \mathrm{~mm}$. For the decisive $y$-stresses, which cause a longitudinal surface crack at the top surface, it is: $\sigma=2.58 \mathrm{~N} / \mathrm{mm}^{2}, E_{\mathrm{cm}}(t)=30000 \mathrm{~N} / \mathrm{mm}^{2}$ and the depth can be assumed with $1 \mathrm{~m}$ as well. In this particular case with significant decreasing restraint over the width only one crack in the centre axis is to be expected. Therefore, half of the whole width of the member is to be considered as distance between the cracks. This indicates a crack width of $2.58 \mathrm{~N} / \mathrm{mm}^{2} / 30000 \mathrm{~N} / \mathrm{mm}^{2} \times 16 \mathrm{~m} / 2 \times 10^{3}=0.69 \mathrm{~mm}$.

\subsection{Conclusions for the design}

The determined cracking pattern can be seen as a surface problem that occurs early around one month. The crack width without consideration of the beneficial effect of reinforcement ranges between $0.15 \mathrm{~mm}$ for transversal cracks around the upper half of the member and $1.0 \mathrm{~mm}$ for the longitudinal crack at the top surface. It should be noted, that the detailed crack assessment according to (Schlicke, 2014) and (Schlicke and Tue, 2015) was able to predict the higher risk of the occurrence of a significant longitudinal crack next to the occurrence of less significant transversal cracks. A sole comparison of the determined stresses with the present tensile strength would have led to the inappropriate conclusion that transversal cracks are more pronounced due to the higher stressing in $x$-direction.

Later, these cracks will close again with the temperature equalization of the core, which is indicated in the FE results with a compressing of the surface zone beginning after 5 month. The determined surface cracks are no risk for stability at any time. And in the service life the crack width is suitably small in order to provide a durable surface. Thus, no explicit reinforcement is needed for the crack control and the amount of minimum reinforcement can be optimized by aiming at an unreinforced construction.

\subsection{Comparison with observations}

In 2015, the new Botlek bridge in The Netherlands was finished; it had been built on foundations of similar dimensions like the pier investigated. Just before the pier cap had been constructed, the top surface of the pier was inspected. There, a bigger longitudinal crack running over nearly the whole member length as well as several smaller transversal cracks were detected. Both the longitudinal crack as well as the transversal cracks accord well with the geometrically set cracking-pattern that was derived from the analysis as shown before. The crack depth of the longitudinal crack was observed by taking several core hole drillings. The longitudinal surface crack reached depths between 1 and $2.6 \mathrm{~m}$.

\section{CONCLUSION AND OUTLOOK}

This contribution presented a comprehensive approach for the assessment of hardening-induced cracking risks of very thick concrete members. Such members are, among other applications, typical for large bridge foundations. In this contribution comprehensive investigations of hardening-induced cracking risks of a very thick bridge pier were presented. The thermomechanical material model, the volumetric FE calculation model, and an analysis of the results were shown in detail. This analysis confirms the expectation that hardening-induced restraint stresses in bloc-like members are predominantly eigenstresses, because low restraint forces and moments result. These eigenstresses are self-balanced and vanish at the beginning of (micro)cracking in the surface zone. The resulting stresses from restraint forces and moments are significant in the $x$-direction but do not exceed the concrete's tensile strength; therefore, macro-cracks can be excluded.

In the case of the bridge foundation considered, it can be concluded that there is no explicit reinforcement needed for crack control. Thus, the amount of minimum reinforcement can be optimized by aiming at an unreinforced construction. 


\section{REFERENCES}

ACI 116R (2000) Cement and Concrete Terminology. ACI Committee 116, American Concrete Institute, Farmington Hills, USA

Bažant, Z.P. - Wu, S. T. (1973) Dirichlet Series Creep Function for Aging Concrete. Proceedings of the American Society of Civil Engineers, pp. 367-387, Reston (Virginia), USA.

Freiesleben, H. - Hansen, P. - Pedersen, E. J. (1977) Måleinstrument til Kontrol af betons hoerding (Measuring Instrument for Control of Concrete Cure). Nordisk Beton, No. 1, pp. 21-25, Stockholm, Sweden [in Swedish].

Heinrich, P. J. - Schlicke, D. (2014) Normative Regelungen zur unbewehrten Ausführung von massigen Betonbauteilen (Design specifications for the construction of unreinforced concrete members). Proceedings of $2^{\text {nd }}$ Grazer Betonkolloquium, Graz, University of Technology, Austria [in German].

Heinrich, P. J. - Schlicke, D. (2016) Hardening induced stresses in very thick concrete members - insights from comprehensive FE-studies. Proceedings of the International RILEM Conference MSSCE 2016, Segment of Service Life of Cement-Based Materials and Structures Vol. 1, pp. 249-258, Copenhagen, Denmark.

Heinrich, P. J. (in press, 2018) Effiziente Berechnung viskoelastischer Spannungen in gezwängten Betonbauteilen (Efficient method for determining viscoelastic stresses in restraint concrete members), Graz, University of Technology, Austria [in German].

Jędrzejewska, A. - Bebodjema, F. - Lacarrière, L. - Azenha, M. - Schlicke, D. - Dal Pont, S. - Delaplace, A. - Granja, J. - Hájková, K. - Heinrich, P.J. - Sciumè, G. - Strieder, E. - Stierschneider, E. - Šmilauer, V. - Troyan, V. (2018) COST TU1404 benchmark on macroscopic modelling of concrete and concrete structures at early age: Proof-of-concept stage. Construction and Building Materials, Vol. 174, pp. 173-189, doi: 10.1016/j.conbuildmat.2018.04.088

Jirásek, M. - Havlásek, P. (2014) Accurate approximations of concrete creep compliance functions based on continuous retardation spectra. Computers \& Structures, Vol. 135, pp. 155-168, doi: 10.1016/j.compstruc.2014.01.024
Jonasson, J. E. (1984) Slipform construction - calculation for assessing protection against early freezing. Swedish Cement and Concrete Research Institute, Fo/Research, Stockholm, Sweden.

ÖNORM EN 1992-1-1 (2011) Eurocode 2: Design of concrete structures - Part 1-1: General rules and rules for buildings. Österreichisches Normungsinstitut, Vienna, Austria.

Schlicke, D. (2014) Mindestbewehrung zwangbeanspruchter Betonbauteile unter Berücksichtigung der erhärtungsbedingten Spannungsgeschichte und der Bauteilgeometrie (Minimum reinforcement of restraint concrete members considering the hydration-caused stress-history and geometry). Graz, University of Technology, Austria, doi: 10.3217/978-3-85125-363-4 [in German].

Schlicke, D. - Tue, N. V. (2015) Minimum reinforcement for crack width control in restrained concrete members considering the deformation compatibility. Structural Concrete, Vol. 16, doi: $10.1002 /$ suco.201400058

Wesche, K. (1993) Baustoffe für tragende Bauteile - Band 2: Beton, Mauerwerk (nicht-metallische-anorganische Stoffe) (Building materials for structural members - Part 2: Concrete, Masonry (non-metallic-inorganic materials)). Bauverlag GmbH Wiesbaden und Berlin, 3. Ed., Berlin, Germany [in German].

ZTV-W215 (2012) Zusätzliche Technische Vertragsbedingungen Wasserbau $(\mathrm{ZTV}-W)$ für Wasserbauwerke aus Beton und Stahlbeton (Leistungsbereich 215) (Additional technical conditions of contract in civil engineering hydraulics for hydraulic structures from concrete and reinforced concrete (work section 215)). Bundesministerium für Verkehr, Bau und Stadtentwicklung, Abteilung Wasserstraßen, Schifffahrt, Karlsruhe, Germany [in German]. 